\title{
Selected abbreviations
}

$\begin{array}{ll}\text { 3D } & \text { three-dimensional } \\ \text { CEO } & \text { chief executive officer } \\ \text { CFIUS } & \text { Committee on Foreign Investment in the United States } \\ \text { EFTA } & \text { European Free Trade Association } \\ \text { EIB } & \text { European Investment Bank } \\ \text { EMU } & \text { economic and monetary union } \\ \text { ERDF } & \text { European Regional Development Fund } \\ \text { EU } & \text { European Union } \\ \text { FDI } & \text { foreign direct investment } \\ \text { FIRA } & \text { Foreign Investment Review Agency } \\ \text { GATS } & \text { General Agreement on Trade in Services } \\ \text { GATT } & \text { General Agreement on Tariff and Trade } \\ \text { GDP } & \text { gross domestic product } \\ \text { GMO } & \text { genetically modified organism } \\ \text { GONGO } & \text { government organised non-governmental organisation } \\ \text { GVC } & \text { global value chain } \\ \text { IIT } & \text { intra-industry trade } \\ \text { IMF } & \text { International Monetary Fund } \\ \text { IRS } & \text { Internal Revenue Service } \\ \text { IT } & \text { information technology } \\ \text { LDC } & \text { less developed country } \\ \text { MAI } & \text { Multilateral Agreement on Investment } \\ \text { MFN } & \text { most-favoured nation } \\ \text { MNE } & \text { multinational enterprise } \\ \text { NAFTA } & \text { North American Free Trade Agreement } \\ \text { NGO } & \text { non-governmental organisation } \\ \text { NTB } & \text { non-tariff barrier } \\ \text { OECD } & \text { Organisation for Economic Co-operation and Development } \\ \text { PANEURO } & \text { Pan-European Cumulation System } \\ \text { PC } & \text { personal computer } \\ \text { R\&D } & \text { research and development } \\ \text { SITC } & \text { Standard International Trade Classification } \\ \text { SMEs } & \text { small and medium-sized enterprises } \\ \text { STEM } & \text { science, technology, engineering and mathematics } \\ \text { TBT } & \text { WTO Agreement on Technical Barriers to Trade } \\ \text { TFEU } & \text { Treaty on the Functioning of the European Union } \\ \text { TiVA } & \text { trade in value added } \\ \text { TNC } & \text { transnational corporation } \\ \text { TPP } & \text { Trans-Pacific Partnership } \\ \text { TRIMs } & \text { Trade-Related Investment Measures } \\ & \end{array}$



UN
United Nations

US United States

USMCA US-Mexico-Canada Agreement

VCR video cassette recorder

WTO World Trade Organization 
Miros lav N. Jovanovic - 9781785368998

Downloaded from PubFactory at 04/26/2023 $02: 11$ : ๑9PM via free access 